\title{
A New Silver Complex with Ofloxacin - Preliminary Study
}

\author{
Rusu Aura1*, Popescu Gabriel-Cosmin², Imre Silvia ${ }^{3}$, Ion Valentin ${ }^{3}$, Vancea Szende ${ }^{4}$, Grama Anda- \\ Lavinia $^{5}$, Kelemen Hajnal ${ }^{1}$, Hancu Gabriel ${ }^{1}$
}

1 University of Medicine and Pharmacy of Tîrgu Mureș, Faculty of Pharmacy, Department of Pharmaceutical Chemistry

2 University of Medicine and Pharmacy of Tîrgu Mureș, Faculty of Pharmacy, student

${ }^{3}$ University of Medicine and Pharmacy of Tîrgu Mureș, Faculty of Pharmacy, Department of Analytical Chemistry

4 University of Medicine and Pharmacy of Tîrgu Mureș, Faculty of Pharmacy, Department of Physical Chemistry

5 University of Medicine and Pharmacy of Tîrgu Mureș, Faculty of Pharmacy, Department of General and Inorganic Chemistry

Objective: Silver complexes of antibacterial quinolones have the potential advantage of combining the antibacterial activity of silver and fluoroquinolones. The objective of our study was the preparation and the preliminary physico-chemical characterization of a silver complex with ofloxacin. Methods: To achieve our goals several spectroscopic methods (ultraviolet spectrophotometry, mass spectrometry, and Fourier transform infrared spectroscopy) and thermal methods (differential scanning calorimetry and thermogravimetric analysis) were used in order to elucidate the chemical structure of the complex. Results: Using mass spectrometry we established the stoichiometric ratio silver:ofloxacin as 1:2. Experimental data suggest a particular coordination for ofloxacin, as a monodentate ligand, in the formation of a complex with silver, through the nitrogen atom from the methyl-piperazine cycle. Conclusions: The obtained complex has a chemical structure likely $\left[\mathrm{Ag}(\mathrm{Ofloxacin})_{2}\right] \mathrm{NO}_{3}$, requiring evaluation through other physico-chemical methods.

Keywords: fluoroquinolones, ofloxacin, silver, metalcomplex, silver nitrate

Received: 23 July 2015 / Accepted: 3 September 2015

\section{Introduction}

Due to the excellent chelating properties of quinolone antibacterial several metal complexes of these substances were synthesized and studied for their possible antibacterial and antifungal activities. The silver ion is known for its antibacterial and antifungal properties. Fluoroquinolones are synthetic antibacterial agents, with broad spectrum activity, good oral absorption and bioavailability. The 4-oxo and 3-carboxyl groups of fluoroquinolones offer excellent chelating properties for metal ions. Silver complexes of fluoroquinolone antibacterial have the advantage of combining the antibacterial activity of the silver ion with the one of the fluoroquinolone. There are a large number of studies on the complexation of antibacterial fluoroquinolones with metal ions using different metals [1]. Metal complexes have been synthesized with antimicrobial activity equal to or greater with the corresponding quinolone antibacterial. Research on the fluoroquinolone metal complexes has revealed also other biological effects: antifungal, antiparasitic, anticancer, anti-inflammatory, antioxidant and even insulin mimetic [2-4]. In the category of metal complexes with promising therapeutic effects are included those containing silver [5-10].

Complexation of antibacterial quinolones with silver combines the antibacterial activity of $\mathrm{Ag}$ (I) with the one of the quinolone. This complexation presents a particular coordination with the quinolone as the monodentate ligand

* Correspondence to: Aura Rusu

E-mail: aura.rusu@umftgm.ro through the N4'-piperazine atom or possibly through a complex polymeric form, different from most other metal complexes of quinolone antibacterials. Although the silver bactericide potential is known from ancient times, only a few studies have used this metal ion to obtain quinolone antibacterial metal complexes $[1,11]$.

Antibacterial agents with new chemical structures are believed to be less susceptible to the occurrence of bacterial resistance mechanisms, consequently metal complexes of fluoroquinolone antibacterials can be promising therapeutic alternatives in the future.

Ofloxacin (OFL) (Figure 1) ((RS)-7-fluoro-2-methyl6-(4-methylpiperazin-1-yl)-10-oxo-4-oxa-1-azatricyclotrideca-5(13),6,8,11-tetraene-11-carboxylic acid), is a second generation fluoroquinolone, used in therapy as a racemic mixture. Ofloxacin is effective against aerobic Gram-positive microorganisms (Staphylococcus aureus, Streptococcus pneumoniae), aerobic Gram-negative microorganisms (Escherichia coli, Haemophilus influenzae,<smiles>C[C@H]1COc2c(N3CCN(C)CC3)c(F)cc3c(=O)c(C(=O)O)cn1c23</smiles>

Fig. 1. The chemical structure of ofloxacin 
Klebsiella pneumoniae, and Neisseria gonorrhea) and Chlamydia. It functions by inhibiting DNA gyrase, a type II topoisomerase, and topoisomerase IV, which is an enzyme necessary to separate (mostly in prokaryotes, in bacteria in particular) replicated DNA, thereby inhibiting bacterial cell division. It is used in the treatment of urinary tract, skin and respiratory infections [12].

Due to the specific complexation ability of fluoroquinolones, in the case of OFL several metalic complexes $\left(\mathrm{Mg}^{2+}, \mathrm{Ca}^{2+}, \mathrm{Ba}^{2+}, \mathrm{Ni}^{2+}, \mathrm{Zn}^{2+}, \mathrm{Cu}^{2+}, \mathrm{Co}^{2+}, \mathrm{Pd}^{2+}, \mathrm{Pt}^{2+}, \mathrm{Bi}^{3+}\right)$ have been studied before in terms of antimicrobial activity (including Helicobacter pylori and Mycobacterium tuberculosis), binding to DNA and to albumins [13-21]. At the moment only a few metal complexes with silver of antibacterial quinolones are known: nalidixic acid, pipemidic acid (first generation), pefloxacin, norfloxacin, ciprofloxacin (second generation), moxifloxacin (fourth generation) [5,6,11,22-24].

The aim of this study was to obtain and characterize physico-chemically a complex with OFL with silver, metal ion which to date has not been studied in complexation with OFL. A synthesis method of the metalic complex was selected and adapted using silver nitrate and ammonia. The characterization of the metal complex was carried out by several methods: spectroscopic methods (ultraviolet spectrophotometry, mass spectrometry, and Fourier transform infrared spectroscopy) and thermal methods (differential scanning calorimetry and thermogravimetric analysis) in order to elucidate the chemical structure and to evaluate the behavior of the newly obtained compound in comparison with OFL.

\section{Methods \\ Materials}

The materials were purchased as follows: ofloxacin (OFL) from Ranbaxy Laboratories Limited (India) and silver nitrate $\left(\mathrm{AgNO}_{3}\right)$ from SC UTCHIM SRL (România). Both substances were of pharmaceutical grade. Other reagents used were: methanol (GR p.a., Lach-Ner, Czech Republic), and ammonia 25\% CP (Microchim, Romania). All reagents and solvents were of analytical grade.

\section{Synthesis of the silver complex}

$1 \mathrm{mM}$ OFL and $0.5 \mathrm{mM} \mathrm{AgNO}_{3}$ were dissolved in $50 \mathrm{~mL}$ concentrate ammonia and $100 \mathrm{~mL}$ distilled water, and maintained on a boiling water bath with reflux condenser for 8 hours. The resulting yellow solution was concentrated on a boiling water bath and the obtained substance was dried in an oven at $80{ }^{\circ} \mathrm{C}$ for 3 hours, and then kept in the desiccator for 3 days with $\mathrm{CaCl}_{2}$ dehydrated protected from light. The synthesis method of the metal complex was adapted after the method described by Li YX et al [6].

\section{Analysis Methods and Apparatus}

Ultraviolet (UV) spectrophotometry. UV spectra were recorded on a spectrometer UV-VIS Specord 210 spec- trometer (Analytik Jena, Germany) and processed using WinASPECT software (Analytik Jena, Germany). We recorded the spectra of the following solutions: $0.002 \mathrm{mM}$ OFL compared to $\left[0.002 \mathrm{mM} \mathrm{OFL}+0.001 \mathrm{mM} \mathrm{AgNO}_{3}\right]$ dissolved in methanol. Also the UV spectrum of OFL was registered in comparison with the obtained silver metal complex; both substances are dissolved in distilled water.

Mass spectrometry (MS). Mass spectra were determined with an Agilent 6410 Triple Quadrupole detector (Agilent Technologies, USA) with electrospray ionization (ESI) and vacuum pump. The recorded data were processed using MassHunter software. Conditions of the ionization source were: gas flow $10 \mathrm{~L} / \mathrm{min}, 50 \mathrm{psi}, 350^{\circ} \mathrm{C}, 4000 \mathrm{~V}$, ESI +, with a full scan on the field 100-1500 amu data acquisition module.

Fourier-transformed infrared (FT-IR) spectroscopy. FT-IR spectra were recorded on a spectrometer FT-IR Thermo Nicolet (USA) and processed using Omnic V.6 software, in the range of $400-4000 \mathrm{~cm}^{-1}$.

Differential Scaning Calorimetry (DSC) analysis. DSC curves were recorded on a DSC 60 Shimadzu apparatus, in the range of $30-350^{\circ} \mathrm{C}$, with a temperature increase rate of $10^{\circ} \mathrm{C} / \mathrm{min}$. The weight of the samples was $3 \mathrm{mg}$.

Thermogravimetric analysis (TGA) and Derivative Thermaogrvimetric (DTG) analysis was carried out using a Mettler Toledo TGA/DSC Thermogravimetric Analyzer. The temperature range was $30-350{ }^{\circ} \mathrm{C}$ with an increase rate of $10^{\circ} \mathrm{C} / \mathrm{min}$. The weights of the samples were between $4-7$ $\mathrm{mg}$. The sample was purged with nitrogen at a rate of 40 $\mathrm{mL} / \mathrm{min}$. Aluminum crucibles were used as standard.

\section{Results}

\section{Synthesis of the complex}

The obtained compound was a solid crystalline substance with bright brown crystals, soluble in concentrated ammonia, in hot water, slightly soluble in $\mathrm{HCl} 10 \%$, very slightly soluble in dimethyl sulfoxide, dimethylformamide, insoluble in $10 \% \mathrm{NaOH}$, ethanol, methanol, and acetone.

\section{UV spectrophotometry analysis}

Preliminary possible changes in UV spectrum of OFL in the presence of silver ions were studied (Figure 2).

Two absorption maxima can be observed, both in the case of OFL $(0.002 \mathrm{mM})$ and OFL with $\mathrm{AgNO}_{3}$ solution $(0.002 \mathrm{~mm} / 0.001 \mathrm{~mm})$, the values are shown in Table I.

After obtaining the metallic complex the UV spectra of this was registered in comparison with the UV spectra of OFL. As solvent we used distilled water, solvent in which we were able to dissolve both substances in the same concentration $\left(3.6 \cdot 10^{-4} \mathrm{~g} \%\right)$. Absorption UV maxima of OFL and of the obtained complex were very similar (Figure 3).

\section{MS analysis}

During MS analysis the capillary voltage was changed in the 3000-4000 V domain, the temperature in the ionization source were in the $300-350{ }^{\circ} \mathrm{C}$ domain without sig- 


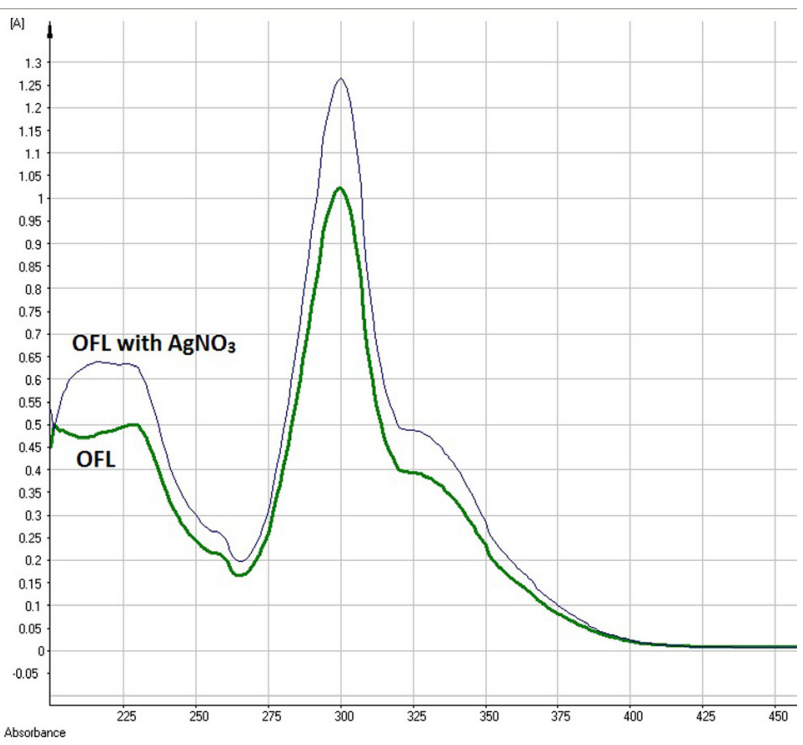

Fig. 2. UV spectra of OFL $(0,002 \mathrm{mM})$ and OFL with AgNO3 $(0,002$ $\mathrm{mM} / 0,001 \mathrm{mM}$ ) in methanol

Table I. Absorption UV maxima of OFL and OFL + AgNO3 (dissolved in methanol)

\begin{tabular}{cccccc}
\hline Substance & $\begin{array}{c}\lambda_{1} \\
(\mathrm{~nm})\end{array}$ & $\begin{array}{c}\text { Absorbance } \\
(1)\end{array}$ & $\begin{array}{c}\lambda_{2} \\
(\mathrm{~nm})\end{array}$ & $\begin{array}{c}\text { Absorbance } \\
(2)\end{array}$ & $\begin{array}{c}\text { Concentrations } \\
{[\mathrm{mM}]}\end{array}$ \\
\hline $\mathrm{OFL}$ & 228 & 0,500 & 300 & 1,023 & 0,002 \\
$\mathrm{OFL}+\mathrm{AgNO}_{3}$ & 226 & 0,633 & 300 & 1,264 & $0,002 / 0,001$ \\
\hline
\end{tabular}

nificant changes in the spectrum. The full scan type mass spectrum at $4000 \mathrm{~V}$ and $350{ }^{\circ} \mathrm{C}$ of the sample analyzed was identified $\mathrm{m} / \mathrm{z} 830.9$ corresponding to a ratio molecular silver ion:OFL of 1:2.

\section{FT-IR spectroscopy analysis}

The FT-IR spectra of OFL and of the obtained complex were registered and compared (Table II).

Table II. The different registred IR frequences $\left(\mathrm{cm}^{-1}\right)-\mathrm{OFL}$ and complex with silver

\begin{tabular}{lcc}
\hline Band position $\left(\mathrm{cm}^{-1}\right)$ & & \\
OFL & OFL-silver complex & Assignments \\
\hline- & $3650-3750$ & $\mathrm{v}(-\mathrm{OH})$ \\
2785 & - & $\mathrm{v}(\mathrm{N}-\mathrm{H})$ \\
1712 & 1708 & $\mathrm{v}(\mathrm{C}=\mathrm{O})_{\text {carb }}$ \\
1621 & 1621 & $\mathrm{v}(\mathrm{C}=\mathrm{O})_{\text {py }}$ \\
- & 1395 & $\mathrm{v}\left(\mathrm{NO}_{2}\right)$ \\
1288 & 1288 & $\mathrm{v}(\mathrm{C}-\mathrm{F})$ \\
- & 1033 & $\mathrm{v}\left(\mathrm{NO}_{2}\right)$ \\
\hline
\end{tabular}

\section{DSC analysis}

We registered and compared the DSC curves of OFL, $\mathrm{AgNO}_{3}$ and of the obtained complex (Figure 4).

\section{TGA and DTG analysis}

TGA of the investigated metal complex is useful to gather information about the stability of the complex. Thermodegradation of the complex had a first decomposition stage only in the temperature range $230-260^{\circ} \mathrm{C}$ with a loss of

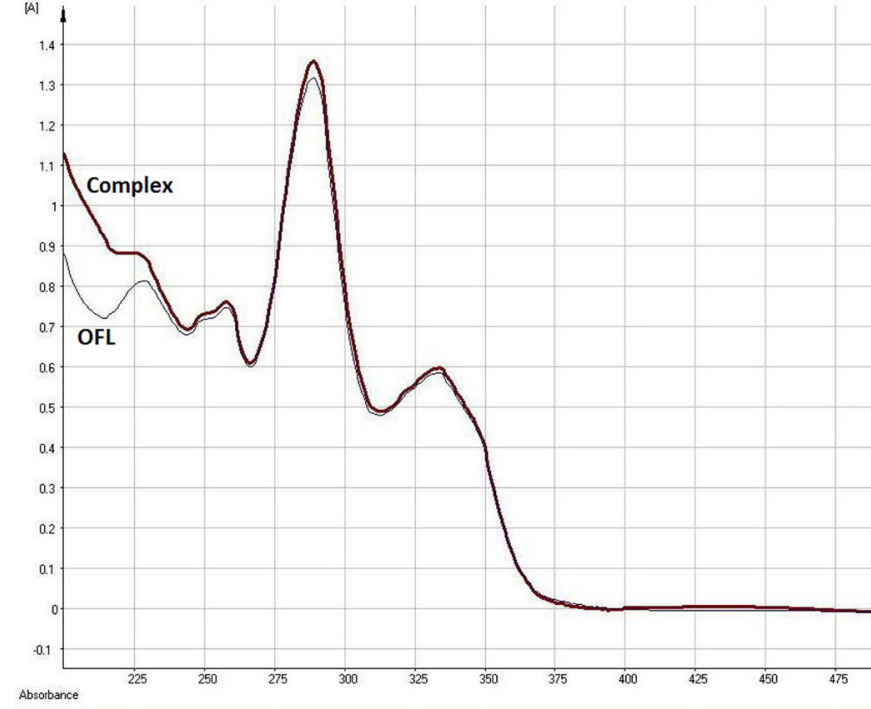

Fig. 3. The UV spectra of the obtained complex in comparison with OFL

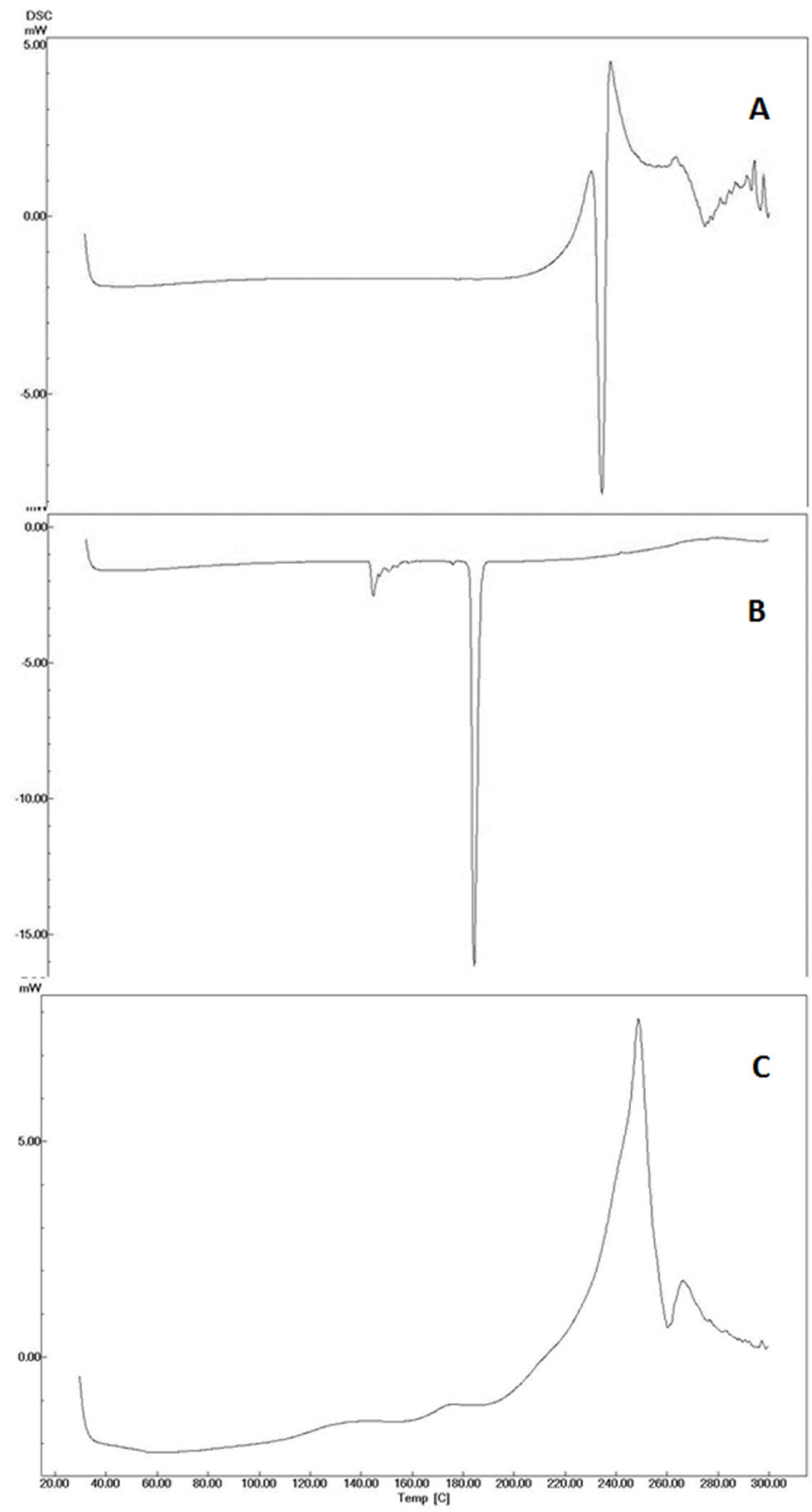

Fig. 4. DSC curves of OFL (A), AgNO3 (B) and obtained complex (C) 
approximately $8.81 \%$ of the weight, and a degradation constant up to $350^{\circ} \mathrm{C}$, with a weight loss of $21 \%$. DTG analysis exhibit an endothermic peak and two exothermic peaks, different from the OFL and $\mathrm{AgNO}_{3}$ records (Figure 5).

\section{Discussion}

\section{Synthesis of the complex}

Obtaining a homogeneous silver complex with ofloxacin is difficult because it is necessary to find a suitable stoichiometric formula. The majority of variants suggested by the literature, started from the premise of ratio silver:OFL $1: 2$, where OFL is a monodentate ligand, suggested by Li Y.-X. et al, without excluding the possibility of $1: 1$, $2: 1$ ratios or other variations $[6,22]$. The ammonia environment seems to positively influence the formation of the metal as $\mathrm{Ag}+$ ion is included in the initial complex $\left[\mathrm{Ag}\left(\mathrm{NH}_{3}\right)_{2}\right] \mathrm{NO}_{3}$. We tried a variant without ammonia solution, but without obtaining a complex. In addition the stability of the complex is influenced by the working conditions: temperature, oxygen from the atmosphere, which can generate potentially $\mathrm{Ag}_{2} \mathrm{O}$ formation (cubic crystals, black-brown) relatively easily decomposed to $\mathrm{Ag}$ and $\mathrm{O}_{2}$ $\left(\mathrm{Ag}_{2} \mathrm{O} \rightarrow 2 \mathrm{Ag}+1 / 2 \mathrm{O}_{2}\right)$. The formation of $\mathrm{AgO}$ (black powder containing $\mathrm{Ag}^{+}$and $\mathrm{Ag}^{3+}$ ), in which +1 and +3 the silver oxidation state it is unlikely.

The final compound obtained is a crystalline solid substance with slightly bright brown crystals, with an indicative solubility in various solvents previously presented.
The aqueous solution obtained by dissolving $1 \mathrm{mg}$ substance in $5 \mathrm{ml}$ of the solvent has a neutral $\mathrm{pH}$ (universal indicator strips Merck). The greatest difficulty of this stage is to obtain a homogeneous compound, with a crystalline structure, soluble in different solvents.

\section{UV spectra analysis}

The UV spectra of OFL recorded in acidic and basic medium, show hypsochrome shifts of absorption maxima in comparison with the spectrum recorded in methanol. In basic medium occurs an increase in the absorption band of the third absorption maximum (due perhaps to the formation of a sodium salt). The tricyclic chemical structure (quinoline nucleus condensation with a heterocycle containing an oxygen atom) brings the possibility of transitions. The absorption maximum of OFL corresponds to the chromophore which includes the nitrogen atom (position 4) and 6-carboxyl group (the numbering of the atoms according to the monograph of the European Pharmacopoeia). The UV absorption maxima of OFL correspond with those from the literature (Table III) $[25,26]$.

There is a slight hyperchromic shift in the case of the UV spectrum of the OFL with silver nitrate solution in methanol in comparison with the OFL spectrum, but the modification of the UV spectrum cannot be considered significant. This shows that no major structural changes occur in the presence of silver ions. The compound synthesized was dissolved in hot water; therefore, we preferred to compare the absorption peak with the one of OFL in this

Table III. The absorbtion maxima of OFL

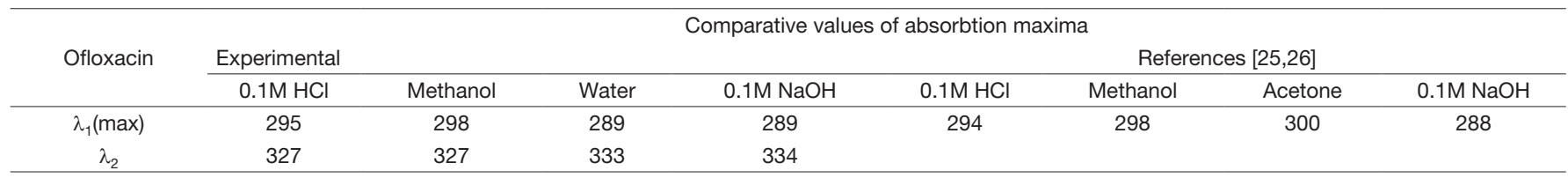

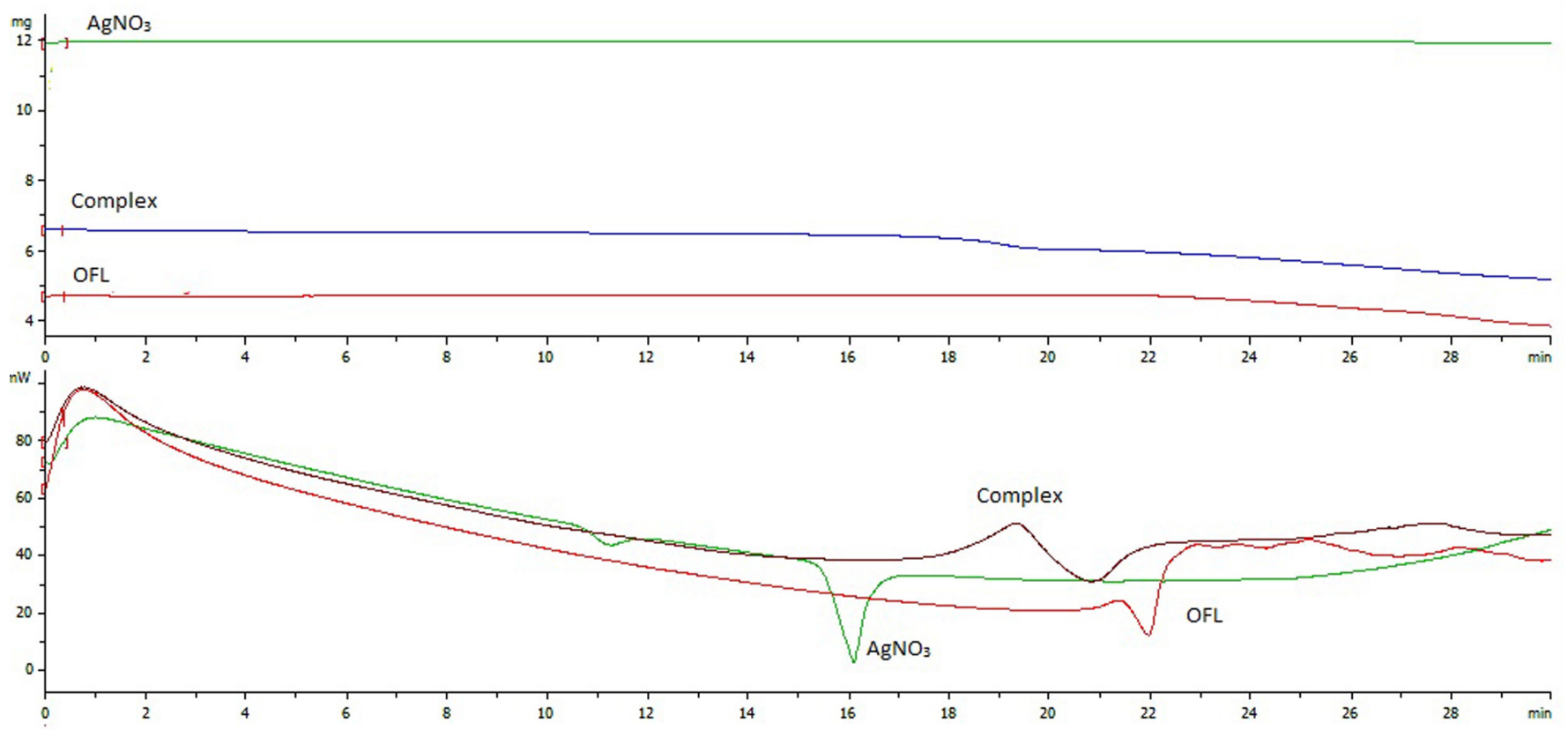

Fig. 5. TGA/DTG curves of OFL, $\mathrm{AgNO}_{3}$ and complex 
solvent. No changes of the UV spectra of the complex were observed in comparison to OFL. Anyway, even if OFL became a monodentate ligand in the studied complex, this is not visible in the UV light, as silver ion does not absorb in the UV domain.

\section{MS spectra analysis}

In general, antibacterial quinolones may become ligands for divalent and trivalent cations, with 3-carboxyl and 4-oxo as chelating groups (in a stoichiometric ratio of metal:ligand of $1: 1,1: 2$ or less frequent, 1:3,1:4), but also through N'4 nitrogen atom from the piperazine substituent. The structure of a metal complex of silver with OFL has not been published yet. By association with patterns obtained so far using OFL, in this study, it is possible to obtain a compound with a stoichiometric metal: ligand of $1: 2$ or $1: 1$ while ratio of $1: 3$ is unlikely [13-21,27]. In the mass spectrum $(\mathrm{m} / \mathrm{z} 830.9)$ is highlighted the molecular ion $\mathrm{Ag}(\mathrm{OFL})_{2}{ }^{+}$, corresponding to ratio metal:ligand of $1: 2$ combination, and $\mathrm{m} / \mathrm{z} 362.1$ corresponding to the molecular ion of the free OFL. Metal complex is formed in this ratio, but not the entire amount of OFL has been included in the complex and obviously the $\mathrm{Ag}^{+}$ions from $\mathrm{AgNO}_{3}$ have not been fully complexed.

\section{FT-IR Spectroscopy analysis}

FT-IR band assignment for the compound was compared to that of OFL (Table II). In the literature, OFL shows characteristic absorption bands for stretching vibrations of the carboxyl groups $\mathrm{v}(\mathrm{C}=\mathrm{O})_{\text {carb }}$ at 1720 and the pyridone $\mathrm{v}(\mathrm{C}=\mathrm{O})_{\mathrm{py}}$ la $1621 \mathrm{~cm}^{-1}$. Absorption bands attributed to carboxyl group $\mathrm{v}(\mathrm{C}=\mathrm{O})_{\text {carb }}$ can be found both in the complex spectrum $\left(1708 \mathrm{~cm}^{-1}\right)$ and in the one of OFL $\left(1712 \mathrm{~cm}^{-1}\right)$ without noticeable changes in [24,28-30]. The stretching vibration for the pyridone group $\mathrm{v}(\mathrm{C}=\mathrm{O})_{\mathrm{py}}$ mentioned in the literature are assigned to $1621 \mathrm{~cm}^{-1}$ (moxifloxacin) and $1630 \mathrm{~cm}^{-1}$ (norfloxacin) [11,29]. The stretching vibration for the pyridone group $\mathrm{v}(\mathrm{C}=\mathrm{O})_{\mathrm{py}}$ are identical for both the OFL and the complex obtained at $1621 \mathrm{~cm}^{-1}$ [13]. From the assigned comparative values of the FT-IR spectra of the complex and OFL, we can conclude that the carboxyl group is not involved in the formation of the silver complex. OFL shows an average value of absorption band of $2785 \mathrm{~cm}^{-1}$, attributable to the stretching vibration of the nitrogen atom (N'4) from the piperazine substituent [29]. This band is missing from FT-IR spectra of synthesized complex and can suggest involvement in silver ion complexation. Fluorine substitution of the aromatic ring (Ar-H) has an absorption band between $1270-1100 \mathrm{~cm}^{-1}$ representing the vibrations of tension C-F [31]. Both OFL and the synthesized complex have a mean absorption band at $1288 \mathrm{~cm}^{-1}$, which can be assigned to the connection C-F of the tricyclic ring. The metal complexes of antibacterial quinolones, exhibit in general, very broad bands between $3400-3600 \mathrm{~cm}^{-1}$ assigned to $\mathrm{v}(-\mathrm{OH})$, respectively to water molecules coordinated or bound by hydrogen bonds. Spec- trum of the obtained compound exhibits a broad band in the area $3650-3750 \mathrm{~cm}^{-1}$, which can be attributed to the water from the structure of the complex [11,29]. Characteristic bands of the deck bidentate nitrate group $\left(\mathrm{NO}_{3}{ }^{-}\right)$, in the case of complex $\left.\left[\mathrm{Ag}_{2} \text { (norfloxacin }\right)_{2}\right]\left(\mathrm{NO}_{3}\right)_{2}$, are observed at 1384 and $1031 \mathrm{~cm}^{-1}$, assigned to $\mathrm{v}_{\text {as }}\left(\mathrm{NO}_{2}\right)$ and $\mathrm{v}_{\mathrm{s}}\left(\mathrm{NO}_{2}\right)$ [32] .

In the case of our complex, values of $1395 \mathrm{~cm}^{-1}$ and $1033 \mathrm{~cm}^{-1}$ can be attributed to vibration strength for this group, suggesting that the nitrate group is part of the target metal complex. A strong band is observed at $1456 \mathrm{~cm}^{-1}$ corresponding to the stretching vibration $\mathrm{v}(\mathrm{N}=\mathrm{O})$.

\section{DSC/TGA analysis}

OFL it's a racemic mixture with a melting point of 225$227^{\circ} \mathrm{C}[12]$. Determination of the melting point by DSC method $\left(30-350^{\circ} \mathrm{C}\right)$ revealed a melting point for OFL of $270.4^{\circ} \mathrm{C}$ higher than the values found in the literature. The melting point of $\mathrm{AgNO}_{3}$ is $211,91^{\circ} \mathrm{C}$ corresponding with the data from literature [33]. The synthesized compound melted at $211.91{ }^{\circ} \mathrm{C}$, but with an exothermic curve, with a high peak, very different from the one obtained for OFL and $\mathrm{AgNO}_{3}$. The synthesized compound proved to be stable up to $230^{\circ} \mathrm{C}$ when it started to decompose. Decomposition profile is similar to that of other metal complexes of antibacterial quinolone agents. In the first stage there is a possible loss of hydration water molecules (4 molecule), which are not present in the mass spectrum analysis, probably as a consequence of the rapid removal of the ionization chamber. This suggests that these are weakly bound water molecules $[13,32]$. After $260^{\circ} \mathrm{C}$ the degradation continued steadily up to $350^{\circ} \mathrm{C}$. DTG shows an endothermic peak and two exothermic peaks different from the one of $\mathrm{OFL}$ and $\mathrm{AgNO}_{3}$. Linked with the decomposition profile of other metal complexes of FQ, this stage can be considered the step in which $\mathrm{AgF}$ and $\mathrm{Ag}$ (fluoroquinolone) complex are formed, which at much higher temperatures (above $500^{\circ} \mathrm{C}$ ) continues until the formation of $\mathrm{AgF}$ [32].

The $\mathrm{Ag}^{+}$ion (which is a $\mathrm{d}^{10}$ ion) can form a linear complex with two ligands (classic example is $\mathrm{NH}_{3}$, in the $\left.\left[\mathrm{Ag}\left(\mathrm{NH}_{3}\right)^{2}\right]^{+}\right)$. Most of $\mathrm{Ag}^{+}$complexes have a coordination number of 2 , and a linear structure as the $\mathrm{Ag}^{+}$ion has a relatively large mass and a low electric charge, resulting in low electron density. Such an ion doesn't assimilate electronic density of the ligands as easy as those ions that have a high electron density [34]. We can state that the ammonia environment favors the complex formation with OFL. In the absence of ammonia the complex does not form, the mass spectrum showing only the specific free OFL molecular ion. The mass spectrum correlated with the data presented above, suggested that the chemical structure of the complex correspond most likely to a $\left[\mathrm{Ag}(\mathrm{OH})_{2}\right] \mathrm{NO}_{3}$ structure that functions as a monodentate ligand and complexation occurs at the C-nitrogen N'4-methyl-piperazine (Figure O), a structure similar to the silver complex obtained Li Y.X. et al for norfloxacin [6]. 


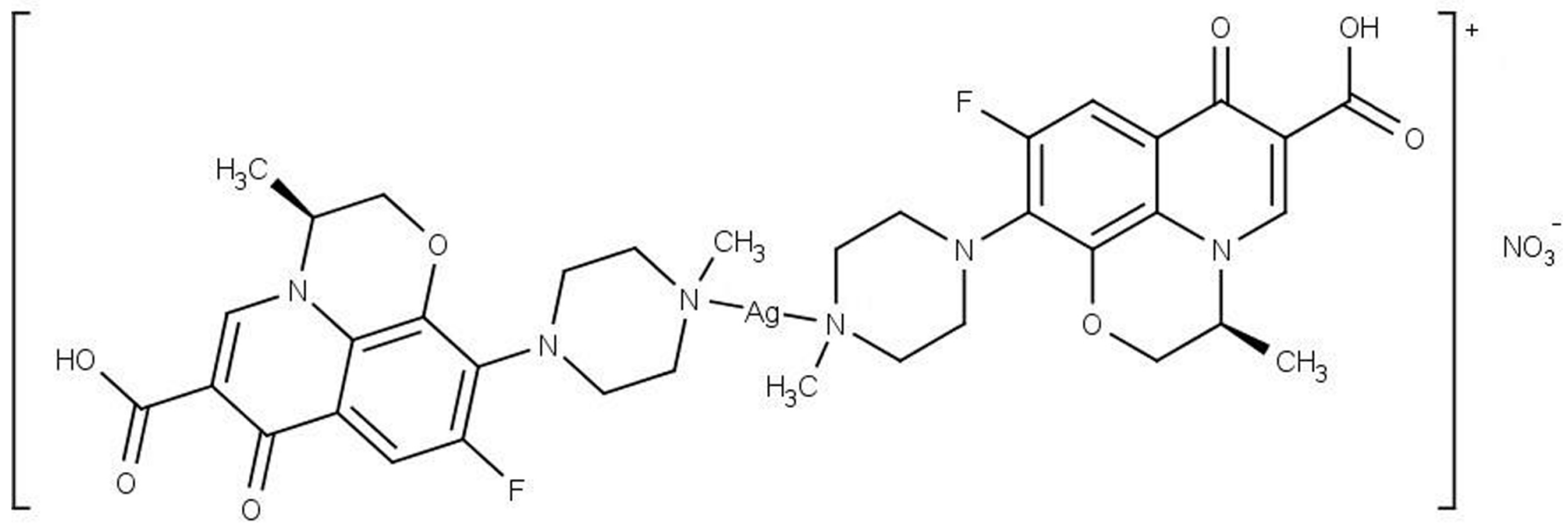

Fig. 6. The proposed structure for the synthesized complex

\section{Conclusion}

During the current study we obtained a silver complex with OFL which was characterized preliminary by several methods: spectrometric methods (UV spectrophotometry, FTIR spectroscopy, mass spectrometry) and thermal methods (DSC and TGA) in order to elucidate the chemical structure. The proposed structure of the complex obtained from the results of physico-chemical analysis is $\left[\mathrm{Ag}(\mathrm{OFL})_{2}\right] \mathrm{NO}_{3}$. Since the synthesis of new molecules with antibacterial activity is an absolute necessity and also a permanent challenge for the medical world due to the alarming increase in bacterial resistance, a metal complex of the silver and OFL may be a promising therapeutic alternative in the future.

\section{Acknowledgements}

The research was supported by the a project funded through Internal Research Grants by the University of Medicine and Pharmacy of Tîrgu Mureş, România (grant contract for execution of research projects nr. 2/23.12.2014)

\section{Conflict of interest}

None to declare.

\section{References}

1. Uivaroși V. Metal Complexes of Quinolone Antibiotics and Their Applications: An Update. Molecules. 2013,18:11153-11197.

2. Singh R, Debnath A, Masram DT, Rathore D. Synthesis and Biological Activities of Selected Quinolone-Metal Complexes. Research Journal of Chemical Sciences 2013;3:83-94.

3. Psomas G, Kessissoglou DP. Quinolones and non-steroidal antiinflammatory drugs interacting with copper(II), nickel(II), cobalt(II) and zinc(II): structural features, biological evaluation and perspectives. Dalton Trans 2013;42:6252-6276.

4. Akinremi CA, Obaleye JA, Amolegbe SA, Adediji JF, Bamigboye $\mathrm{MO}$. Biological activities of some Fluoroquinolones-metal complexes. International Journal of Medicine and Biomedical Research 2012;1:2434.

5. Baenziger NC, Fox Jnr CL, Modak SL. The Structure of Silver Pefloxacin, an Antibiotic Related to Nalidixic Acid. Acta Crystallogr C 1986;42:1505-1509.

6. Li YX, Chen ZF, Xiong RG, Xue Z, Ju HX, You XZ. A mononuclear complex of norfloxacin with silver(l) and its properties. Inorg Chem Commun 2003;6:819-822

7. Rai MK, Deshmukh SD, Ingle AP, Gade AK. Silver nanoparticles: the powerful nanoweapon against multidrug-resistant bacteria. J Appl Microbiol 2012;112:841-852.
8. El-Gamel NE. Silver(I) complexes as precursors to produce silver nanowires: structure characterization, antimicrobial activity and cell viability. Dalton Trans 2013;42:9884-9892.

9. Martínez-Abad A, Sánchez G, Lagaron JM, Ocio MJ. Ligands affecting silver antimicrobial efficacy on Listeria monocytogenes and Salmonella enterica. Food Chem. 2013;139:281-288.

10. Paiva IL, de Carvalho GSG, da Silva AD et al. Silver(I) complexes with symmetrical Schiff bases: Synthesis, structural characterization, DFT studies and antimycobacterial assays. Polyhedron. 2013;62:104-109.

11. Soayed AA, Refaat HM, El-Din DAN. Metal complexes of moxifloxacinimidazole mixed ligands: Characterization and biological studies. Inorganica Chimica Acta. 2013;406:230-240.

12. Al-Omar MA. Ofloxacin, in Brittain HG (ed): Profiles of Drug Substances, Excipients, and Related Methodology. Academic Press, Burlington, 2009;265-298.

13. Macias B, Villa M, Rubio I, Castineiras A, Borras J. Complexes of Ni (II) and $\mathrm{Cu}$ (II) with ofloxacin. Crystal structure of a new Cu (II) ofloxacin complex. J Inorg Biochem. 2001;84:163-170.

14. Macias B, Villa MV, Sastre M, Castiñeiras A, Borras J. Complexes of Co(II) and $\mathrm{Zn}(\mathrm{II})$ with ofloxacin. Crystal structure of $\left[\mathrm{Co}(\mathrm{oflo})_{2}(\mathrm{MeOH})_{2}\right] \cdot 4 \mathrm{MeOH}$. J Pharm Sci. 2002;91:2416-2423.

15. Sagdinc S, Bayari S. Spectroscopic studies on the interaction of ofloxacin with metals. J Mol Struct. 2004;691:107-113.

16. Drevenšek P, Košmrlj J, Giester G, et al. X-ray crystallographic, NMR and antimicrobial activity studies of magnesium complexes of fluoroquinolones - racemic ofloxacin and its S-form, levofloxacin. J Inorg Biochem. 2006;100:1755-1763.

17. Vieira LMM, de Almeida MV, Lourenço MCS, Bezerra FAFM, Fontes APS. Synthesis and antitubercular activity of palladium and platinum complexes with fluoroquinolones. Eur J Med Chem. 2009;44:41074111.

18. Shaikh AR, Giridhar R, Megraud F, Yadav MR. Metalloantibiotics: Synthesis, characterization and antimicrobial evaluation of bismuthfluoroquinolone complexes against Helicobacter Pylori. Acta Pharm. 2009;59:259-271.

19. Živec P, Perdih F, Turel I, Giester G, Psomas G. Different types of copper complexes with the quinolone antimicrobial drugs ofloxacin and norfloxacin: Structure, DNA- and albumin-binding. J Inorg Biochem. 2012;117:35-47.

20. Patel MN, Gandhi DS, Parmar PA. DNA interaction and in-vitro antibacterial studies of fluoroquinolone based platinum(II) complexes. Inorg Chem Commun. 2012;15:248-251.

21. Palazzo F, Giovagnoli S, Schoubben A, Blasi P, Rossi C, Ricci M. Development of a spray-drying method for the formulation of respirable microparticles containing ofloxacin-palladium complex. Int J Pharm. 2013;440:273-282.

22. Chen ZF, Yu LC, Zhong DC, Liang H, Zhu XH. An unprecedented 1D ladder-like silver(l) coordination polymer with ciprofloxacin, Inorg Chem Commun. 2006;9:839-843.

23. Li MT, Sun JV, Sha JQ, Wu HB, Zhang EL, Zheng TY. An unprecedented Ag-pipemidic acid complex with helical structure: Synthesis, structure and interaction with CT-DNA, J Mol Struct. 2013;1045:29-34.

24. Debnath A, Mogha NK, Masram DT. Metal Complex of the FirstGeneration Quinolone Antimicrobial Drug Nalidixic Acid: Structure and Its Biological Evaluation. Appl Biochem Biotechnol. 2015;175:2659- 
2667.

25. Dibbern HW, Müller RM, Wirbitzki E(eds): UV and IR Spectra, Pharmaceutical Substances (UV and IR) and Pharmaceutical and Cosmetic Excipients (IR). Editio Cantor Verlag, Aulendor, 2002;1102

26. Salem H, Fada L, Khater W. Spectrofluorimetric Determination of Certain Fluoroquinolones Through Charge Transfer Complex Formation. American Journal of Pharmacology and Toxicology 2007;2: 18-25.

27. Gouvea LR, Garcia LS, Lachter DR, et al. Atypical fluoroquinolone gold(III) chelates as potential anticancer agents: relevance of DNA and protein interactions for their mechanism of action. Eur J Med Chem. 2012;55:67-73.

28. Dorofeev VL. Infrared spectra and the structure of drugs of the fluoroquinolone group. Pharmaceutical Chemistry Journal (KhimikoFarmatsevticheskii Zhurnal) 2004;38:45-49,2004.

29. Sadeek AS. Synthesis, thermogravimetric analysis, infrared, electronic and mass spectra of $\mathrm{Mn}(\mathrm{II}), \mathrm{Co}(\mathrm{II})$ and Fe(III) norfloxacin complexes. $J$
Mol Struct. 2005;753:1-12.

30. Sousa I, Claro V, Pereira JL, et al. Synthesis, characterization and antibacterial studies of a copper(II) levofloxacin ternary complex. J Inorg Biochem. 2012;110:64-71.

31. Coates G. Interpretation of Infrared Spectra, A Practical Approach, in Meyers RA (ed): Encyclopedia of Analytical Chemistry. John Wiley \& Sons Ltd, Chichester, 2000;10815-10837.

32. Refat MS. Synthesis and characterization of norfloxacin-transition metal complexes (group 11, IB): Spectroscopic, thermal, kinetic measurements and biological activity. Spectrochim Acta A Mol Biomol Spectrosc. 2007;68:1393-1405.

33. O'Neil MJ (ed): The Merck Index - An Encyclopedia of Chemicals, Drugs, and Biologicals. 13th Edition. Whitehouse Station NJ Merck and Co Inc, 2001;1526.

34. House JE - Inorganic chemistry. 2nd Edition, Academic Press, Elsevier Inc. All, 2013;570. 